\title{
УДК 666.3
}

И. Ф. Закиров, А. Д. Никулин, Н. В. Обабков

\section{Толстослойные теплозащитные покрытия}

\section{состава « $\mathrm{ZrO}_{2}-\mathrm{Y}_{2} \mathrm{O}_{3}$-керамическое волокно»}

\section{для защиты конструкционных сплавов}

Предложена технология получения теплозащитных керамических покрытий $\mathrm{ZrO}_{2}-\mathrm{Y}_{2} \mathrm{O}_{3}$, включающая армирование керамики керамическим волокном и металлических подложек с помощью нихромовых спиралей. Проведены исследования микроструктуры, прочности и термостойкости покрытия. Ключевые слова: теплозащитные покрытия, диоксид циркония, оксид иттрия, керамическое волокно, металлические подложки, термостойкость.

\section{Введение}

Для создания теплозащитных покрытий применяется оксидная керамика $\mathrm{ZrO}_{2}-\mathrm{Y}_{2} \mathrm{O}_{3}[1]$. Эффективно работать эти материалы могут, когда они обладают хорошим сцеплением с поверхностью основы. С увеличением толщины слоя керамики повышается эффективность тепловой защиты металлической основы, однако при этом снижается его долговечность в условиях термоударов и термоциклирования. Оксидные толстослойные покрытия на металлах, как правило, отличаются низкой термической стойкостью ввиду того, что при нагреве на границе основа - покрытие возникают значительные термические напряжения [2]. Низкая пластичность керамики не способствует релаксации этих напряжений, а ведет к образованию трещин на границе керамики с основой. Недостаточная адгезия керамического покрытия с металлической основой, как правило, не препятствует распространению трещин на границе между ними и приводит к отслоению покрытия. По мнению авторов, к толстослойным относятся покрытия, толщина которых превышает 1 мм [3].

Для увеличения толщины оксидных слоев с сохранением необходимых требований по термостойкости используют многослойные конструкции. Наиболее распространенными являются, например, внешний слой керамика $\mathrm{ZrO}_{2}-\mathrm{Y}_{2} \mathrm{O}_{3}$ и подслой $\mathrm{Ni}-\mathrm{Cr}-\mathrm{Al}-\mathrm{Y}$, a также градиентные покрытия с переменным содержанием компонентов подслоя и керамики [4].

() Закиров И. Ф., Никулин А. Д., Обабков Н. В., 2018
Технология получения толстослойных композиционных покрытий на основе диоксида циркония

Авторы разработали технологию получения термостойких покрытий на основе $\mathrm{ZrO}_{2}-\mathrm{Y}_{2} \mathrm{O}_{3}$ толщиной более 5 мм, обладающих удовлетворительной адгезией к металлической подложке из нержавеющей стали $12 \mathrm{X} 18 \mathrm{H} 10 \mathrm{~T}$.

Получение композита на основе диоксида циркония для нанесения покрытия. Для получения теплозащитных керамических покрытий использованы порошки состава $\mathrm{ZrO}_{2}-7 \% \mathrm{Y}_{2} \mathrm{O}_{3}$, синтезированные различными способами:

- совместное осаждение аммиаком гидроксидов из растворов нитратов циркония и иттрия;

- термогидролизом раствора нитратов циркония и иттрия при $60{ }^{\circ} \mathrm{C}$ в присутствии серной кислоты;

- гидротермальной обработкой растворов нитратов циркония и иттрия при $p H=8$.

Для повышения термостойкости материала покрытия его армировали дискретными керамическими волокнами, полученными из волокнистого материала с составом $\mathrm{ZrO}_{2}-14-17 \% ; \mathrm{Al}_{2} \mathrm{O}_{3}-50-56 \%$; $\mathrm{SiO}_{2}-27-36 \%$,путем их измельчения в водной среде с использованием миксера. Было определено, что для получения волокон длиной около 200 мкм оптимальное время помола должно составлять не более 15-25 с (рис. 1).

Композит « $\mathrm{ZrO}_{2}-7 \% \mathrm{Y}_{2} \mathrm{O}_{3}$-керамическое волокно» получали по шликерной технологии. Для этого исходные порошки $\mathrm{ZrO}_{2}-7 \% \mathrm{Y}_{2} \mathrm{O}_{3}$ после измельчения в шаровой мельнице смешивали в водной среде с полученным дискретным волокном и сушили 


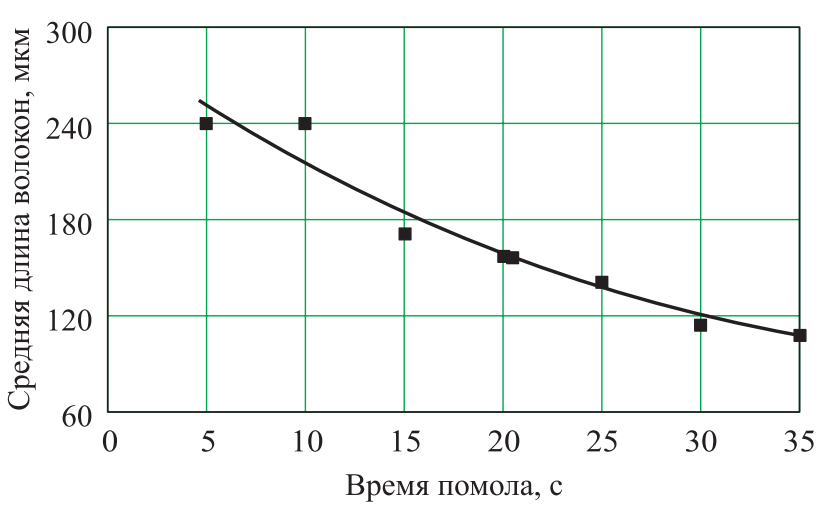

Рис. 1. Зависимость средней длины волокон от времени помола:

$y=0,0881 x^{2}-8,3595 x+289,14 ; R^{2}=0,9521$

до постоянной массы. Волокно вводили в количестве 1-10 масс. \%. Затем из смеси готовили густой шликер, используя в качестве связующего парафин.

На рис. 2 представлены микроструктуры материалов для покрытий, сделанные из порошков, синтезированных различными способами. Исследования показали, что наилучшими характеристиками обладает материал покрытия, полученный из порошка, синтезированного с гидротермальной обработкой. Структура материала более однородна с минимальным количеством дефектов. Такие порошки в дальнейшем использовали для создания толстослойных покрытий.

Нанесение армированного материала на подложку из стали 12X18Н10Т. Для обеспечения сцепления толстослойного керамического покрытия на металлической подложке ее поверхность была подготовлена путем армирования. Использование напаянной металлической сетки для покрытий толщиной более
5 мм малоэффективно, так как при термоциклировании происходит образование трещин по границе керамика - металл, что приводит к преждевременному разрушению и отслоению теплозащитного покрытия [5].

Авторы статьи разработали технологию армирования металлической подложки с помощью металлических спиралей. Для этого на поверхность подложки из нержавеющей стали 12 Х18Н10Т наносили слой высокотемпературного припоя ВПр-11-40Н. Далее на этом слое располагали в определенном порядке спирали из нихрома и проводили пайку в вакууме при температуре $1150{ }^{\circ} \mathrm{C}$ в течение 30 мин. Затем разрезали верхние гребни спиралей, правили образующиеся «усы» с ориентировкой в направлении, перпендикулярном к поверхности подложки (рис. 3). Установлено, что диаметр витков спиралей из нихрома $(d)$ зависит от толщины покрытия $(h)$ и должен составлять

$$
\frac{h}{2}<d<\frac{h}{1,25} .
$$

Шаг витков спиралей $s$ должен составлять величину 3 мм. При $s \leq 2$ происходит значительное увеличение дефектности керамического слоя и технологически затрудняется его нанесение, а при $s>3$ мм снижается эффективность армирования поверхности металлической подложки. Рекомендуемое расстояние между спиралями $b \leq 2 d$.

В дальнейшем на армированную подложку из нержавеющей стали (рис. 4) наносили подслой шликера из смеси порошков никеля и алюминия с содержанием последнего 10-15 масс. \%. После чего - слой густого шликера « $\mathrm{ZrO}_{2}-7 \% \mathrm{Y}_{2} \mathrm{O}_{3}$-керамическое волокно»

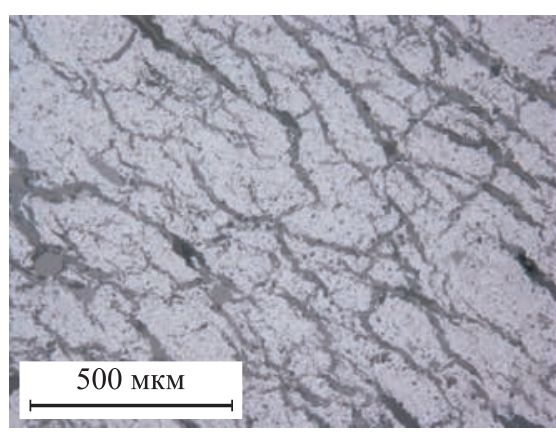

a

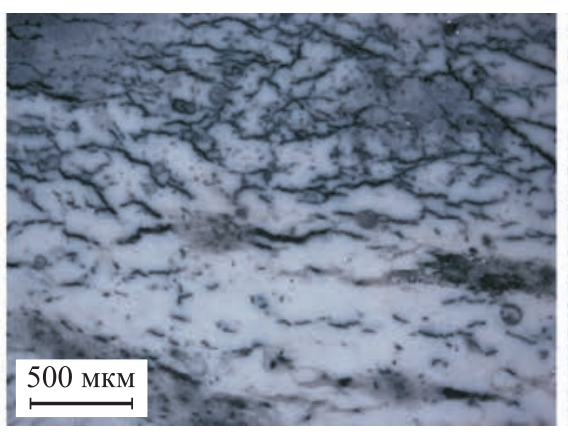

6

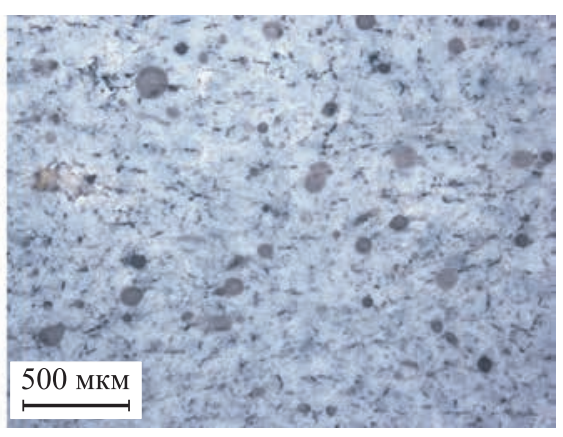

B

Рис. 2. Микроструктура материала покрытий:

а - совместное осаждение; б - термогидролиз; в - гидротермальная обработка 


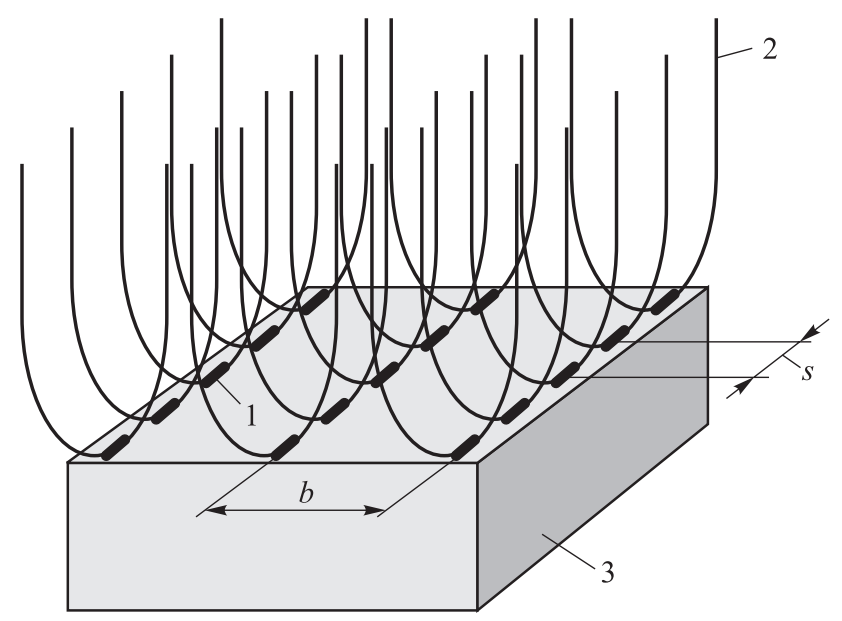

Рис. 3. Схема крепления армирующих элементов к металлической подложке:

1 - места пайки; 2 - армирующие элементы; 3 - подложка

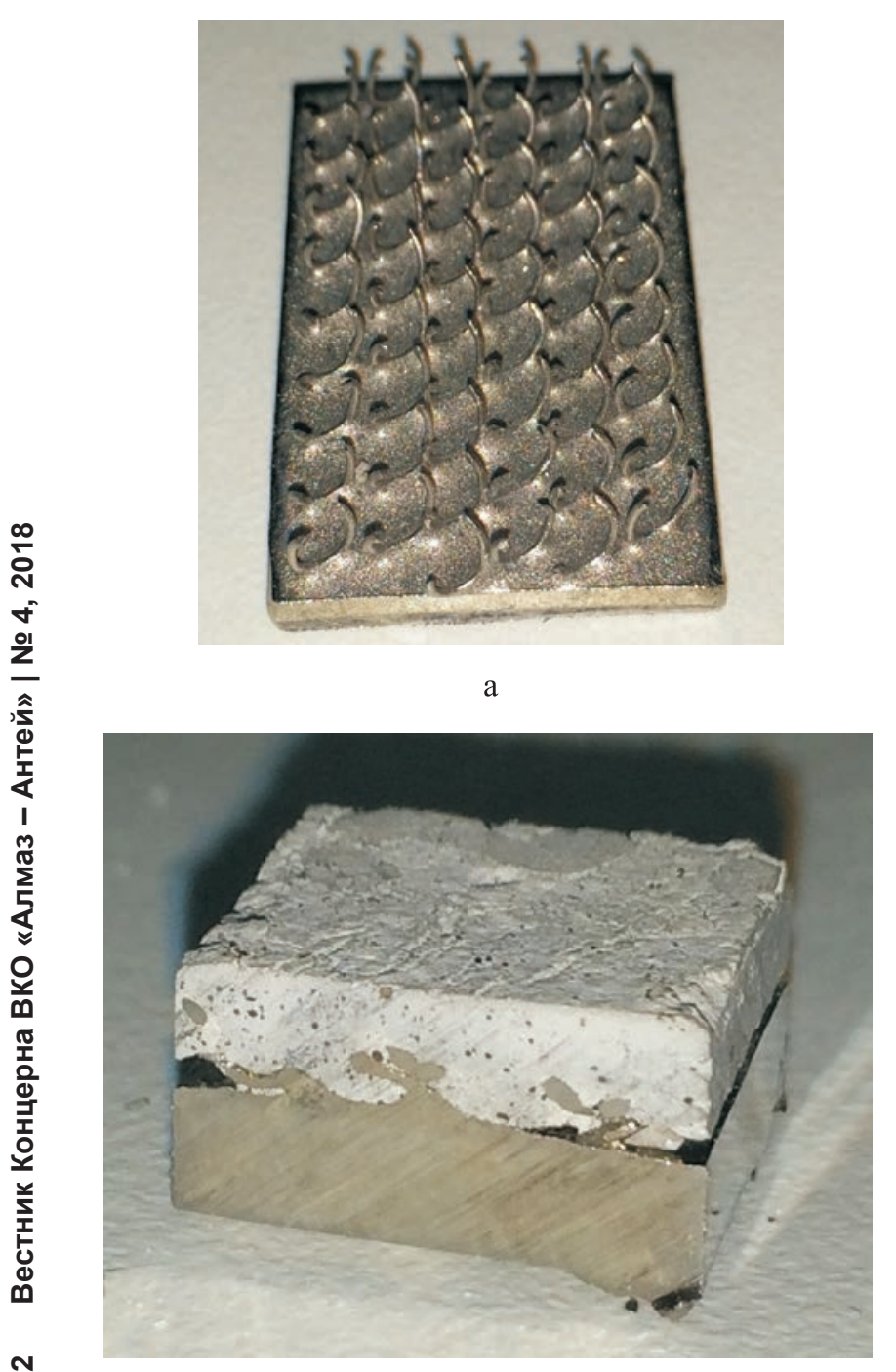

6

Рис. 4. Армированная подложка из нержавеющей стали 12Х18Н10T:

a - перед нанесением покрытия; б - после нанесения покрытия с парафином. Полученную композицию уплотняли путем подпрессовки, сушили и обжигали при температуре $1200{ }^{\circ} \mathrm{C}$ в вакууме. Таким способом можно получать покрытия толщиной 5-10 мм. Микроструктура границы «покрытие - подложка» представлена на рис. 5.

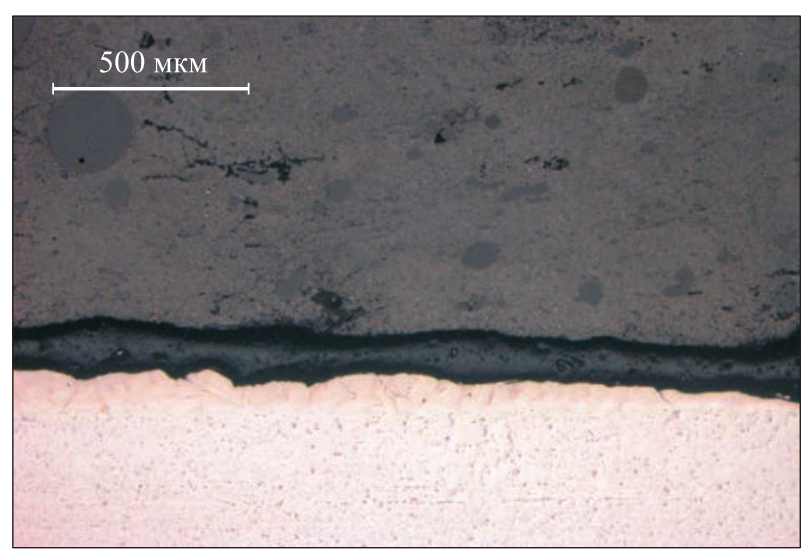

Рис. 5. Микроструктура композитного покрытия « $\mathrm{ZrO}_{2}-7 \% \mathrm{Y}_{2} \mathrm{O}_{3}$-керамическое волокно» на нержавеющей стали 12X18H10T

Одним из недостатков разработанной технологии является низкая температура плавления паяного шва $\left(\sim 1150{ }^{\circ} \mathrm{C}\right)$, удерживающего армирующие элементы металлической подложки. Материал паяного шва представляет собой низкоплавкую эвтектику в системе $\mathrm{Ni}-\mathrm{Fe}-\mathrm{B}-\mathrm{Si}$. Очевидно, что для повышения температуры плавления необходимо снизить концентрацию бора в паяном слое. Для этой цели был проведен диффузионный отжиг подложки с паяным слоем при температуре $1200{ }^{\circ} \mathrm{C}$ в течение 1 и 5 ч. На рис. 6 представлены результаты измерения микротвердости в области границы «паяный слой - подложка». Существенное снижение твердости вблизи этой границы свидетельствует о значительной диффузии $\mathrm{Si}$ и В в глубь подложки и стабилизации паяного слоя повышенной температуре.

В нанесенном подслое из смеси порошков никеля и алюминия в процессе вакуумного отжига при температуре $1200{ }^{\circ} \mathrm{C}$ за счет экзотермической реакции взаимодействия никеля и алюминия происходит образование алюминида никеля $\mathrm{Ni}_{3} \mathrm{Al}$ и частично на границе с подложкой алюминидов железа. Это способствует дополнительному упрочнению керамического слоя с металлической подложкой. 


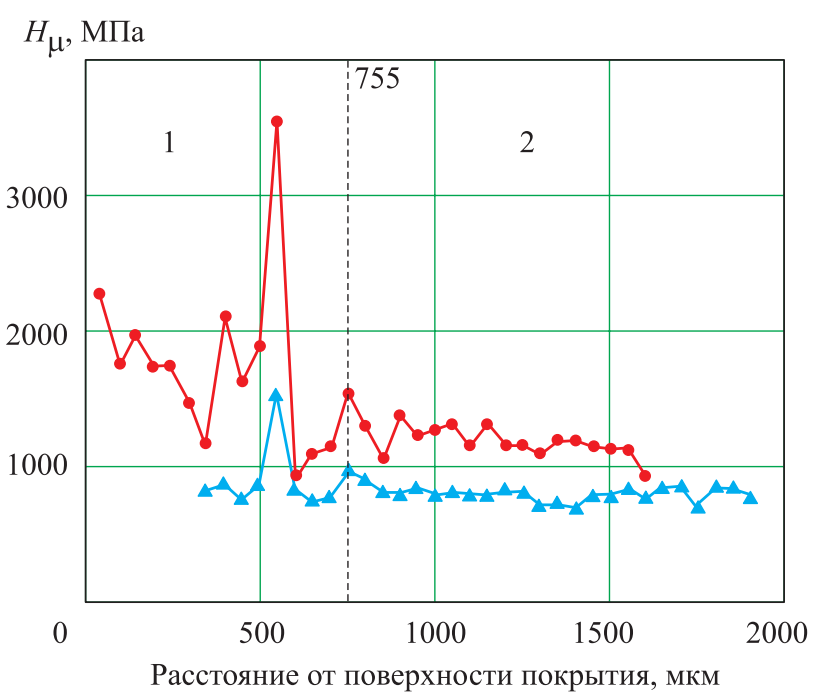

Рис. 6. Микротвердость сплава:

1 - припой; 2 - металл; $\rightarrow-1$ ч; $\rightarrow-5$ ч

Было установлено, что содержание алюминия в смеси должно быть 10-15 масс. \%, при меньшем содержании алюминия упрочнение недостаточно, а при более 15 масс. \% алюминия подслой становится хрупким, что способствовало образованию в зоне взаимодействия большого количества микротрещин. Также установлено, что в процессе подпрессовки происходит частичная деформация изгибом армирующих элементов поверхности «усов», что играет положительную роль. За счет этого керамический слой более плотно поджимается к поверхности подложки и «усы» работают как скобы, дополнительно фиксируя покрытие.

Экспериментально было определено, что оптимальный шаг спиралей составляет 3 мм. При меньшем шаге происходит значительное увеличение дефектности керамического слоя и технологически затрудняется его нанесение, а также невозможно плотное прилега- ние покрытия к основе, образуются широкие зазоры между покрытием и металлической подложкой, что неблагоприятно влияет на прочностные свойства. При испытаниях отрыв покрытия происходит по границе подложка - керамика, жесткость сцепления обеспечивается только наличием армирующих спиралей.

Исследования прочности сцепления покрытий проводили по клеевой методике. Испытания показали, что у образцов с шагом спиралей 3 мм происходит когезионный отрыв по телу покрытия при напряжении около $10 \mathrm{MПа,}$ что свидетельствует о достаточной адгезии получаемых покрытий.

Определены основные характеристики покрытий: плотность, открытая пористость, термостойкость. Наилучшие результаты показал композит состава « $\mathrm{ZrO}_{2}-7 \%$ $\mathrm{Y}_{2} \mathrm{O}_{3}-10 \%$-керамическое волокно». Такой материал выдержал 10 термоциклов (нагрев до $1100{ }^{\circ} \mathrm{C}$, охлаждение в воде) без видимых разрушений, его пористость - $40 \%$, плотность $-3,0$ г $\mathrm{cm}^{3}$. Предел прочности на изгиб составил $20 \mathrm{MПа,} \mathrm{а} \mathrm{после} 10$ термоциклов снизился до $10 \mathrm{MПа.}$

Оценку термостойкости материалов покрытий проводили по значению снижения прочностных свойств материала покрытия в условиях термоциклирования: нагрев до $1100{ }^{\circ} \mathrm{C}$ и охлаждение в воде. Было установлено, что введение керамического волокна до 10 масс. \% ведет к снижению прочностных свойств керамического композита, вероятно, за счет значительного увеличения пористости керамического слоя до 40 \%. Однако повышение содержания волокна способствует получению более стойких материалов,

Влияние содержания волокна в композитах на их свойства

\begin{tabular}{|c|c|c|c|c|}
\hline \multirow{2}{*}{$\begin{array}{c}\text { Содержание волокна, } \\
\text { масс. \% }\end{array}$} & \multirow{2}{*}{ 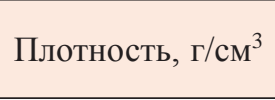 } & \multirow{2}{*}{ Пористость, \% } & \multicolumn{2}{|c|}{ Прочность на изгиб, МПа } \\
\hline & & & После спекания & После 10 термоциклов \\
\hline 1 & 4,8 & 14 & 49 & 2 \\
\hline 2 & 4,2 & 24 & 39 & 4 \\
\hline 3 & 4,1 & 26 & 30 & 5 \\
\hline 5 & 3,8 & 29 & 27 & 7 \\
\hline 7,5 & 3,3 & 35 & 22 & 8 \\
\hline 10 & 3,0 & 40 & 20 & 10 \\
\hline
\end{tabular}


работающих в условиях термоциклирования. При более высоких концентрациях волокна наблюдается неравномерное распределение матричного компонента в объеме композита. Например, композиты с содержанием волокна более 13 масс. \% практически не спекались при температуре $1200{ }^{\circ} \mathrm{C}$ и разрушались при выгрузке из печи. Результаты исследования представлены в таблице.

Были проведены испытания керамических покрытий толщиной 5 мм на нержавеющей стали $12 \mathrm{X} 18 \mathrm{H} 10 \mathrm{~T}$, полученных по разработанной технологии в условиях термоциклирования: нагрев - струей газа $300 \mathrm{~K}$ $\rightarrow 2200 \mathrm{~K}$ в течение 5 с, охлаждение - обдув воздухом $2200 \mathrm{~K} \rightarrow 300 \mathrm{~K}$ в течение $15 \mathrm{c.}$ Результаты испытаний показали, что покрытия выдержали более 5-10 термоциклов без видимых нарушений.

\section{Заключение}

Разработана технология получения толстослойных композитных покрытий « $\mathrm{ZrO}_{2}-7 \%$ $\mathrm{Y}_{2} \mathrm{O}_{3}$-керамическое волокно», обладающих повышенной термостойкостью при термоциклировании.
Экспериментально подобраны оптимальные составы композитов для толстослойных термостойких покрытий.

Определены основные характеристики покрытий: плотность и пористость, прочность на изгиб, термостойкость и адгезионные свойства.

Полученные композитные покрытия могут быть рекомендованы для использования в качестве материалов тепловой защиты.

\section{Список литературы}

1. Михеев С. В., Строганов Г. Б., Ромашин А. Г. Керамические композиционные материалы в авиационной технике. М.: Альтекс, 2002. С. 184. 2. Аппен A. A. Температуроустойчивые неорганические покрытия. Л.: Химия, 1976. 240 с. 3. Бэкман В., Швенк В. Катодная защита от коррозии. М.: Металлургия, 1984. С. 169.

4. Kvernes I. Ceramic coatings as thermal barriers in diesel and gas turbine engine components. Amsterdam: Elsevier, 1987. Pp. 2519-2536.

5. Способ нанесения уплотнительного покрытия / Н. В. Обабков, Р. Т. Галлямов, А. Р. Бекетов и др. Пат. RU № 2287609. Опубл. 20.05.2007. БИ № 14.

Поступила 21.03.18

Закиров Ильсур Фларитович - инженер 2-й категории кафедры «Редкие металлы и наноматериалы» Федерального государственного автономного образовательного учреждения высшего образования «Уральский федеральный университет имени первого Президента России Б. Н. Ельцина», г. Екатеринбург.

Область научных интересов: высокотемпературная керамика и композиционные материалы.

Никулин Андрей Дмитриевич - студент кафедры «Редкие металлы и наноматериалы» Федерального государственного автономного образовательного учреждения высшего образования «Уральский федеральный университет имени первого Президента России Б. Н. Ельцина», г. Екатеринбург.

Область научных интересов: высокотемпературная керамика и композиционные материалы.

Обабков Николай Васильевич - доктор технических наук, профессор кафедры «Редкие металлы и наноматериалы» Федерального государственного автономного образовательного учреждения высшего образования «Уральский федеральный университет имени первого Президента России Б. Н. Ельцина», г. Екатеринбург.

Область научных интересов: высокотемпературная керамика и композиционные материалы. 


\section{Thick-layered heat-protection coatings of the composition “ $\mathrm{ZrO}_{2}-\mathrm{Y}_{2} \mathrm{O}_{3}$-ceramic fiber" for structural alloys protection}

The paper introduces a technology for producing heat-protection ceramic coatings $\mathrm{ZrO}_{2}-\mathrm{Y}_{2} \mathrm{O}_{3}$, including the reinforcement of ceramics with ceramic fiber and metal substrates using nickel-chromium spirals. The microstructure, strength and heat resistance of the coating have been studied.

Keywords: heat-protection coatings, zirconia, yttria, ceramic fibre, metal substrates, heat-resistance.

Zakirov Ilsur Flaritovich - second category engineer, Department of Rare Metals and Nanomaterials, Federal State Autonomous Educational Institution of Higher Education "Ural Federal University named after the First President of Russia B. N. Yeltsin”, Ekaterinburg.

Science research interests: high-temperature ceramics and composite materials.

Nikulin Andrey Dmitrievich - student, Department of Rare Metals and Nanomaterials, Federal State Autonomous Educational Institution of Higher Education "Ural Federal University named after the First President of Russia B. N. Yeltsin", Ekaterinburg.

Science research interests: high-temperature ceramics and composite materials.

Obabkov Nikolay Vasilievich - Doctor of Engineering Sciences, Professor, Department of Rare Metals and Nanomaterials, Federal State Autonomous Educational Institution of Higher Education "Ural Federal University named after the First President of Russia B. N. Yeltsin", Ekaterinburg.

Science research interests: high-temperature ceramics and composite materials. 